\title{
Correlation of dynamic and quasistatic relaxations: The Cox- Merz rule for metallic glass
}

$\operatorname{AUTHOR}(S):$

Kato, Hidemi; Ichitsubo, Tetsu; Igarashi, Hitoshi; Inoue, Akihisa

\section{CITATION:}

Kato, Hidemi ... [et al]. Correlation of dynamic and quasistatic relaxations: The Cox-Merz rule for metallic glass. APPLIED PHYSICS LETTERS 2009, 95(23): 231911.

\section{ISSUE DATE:}

2009-12

URL:

http://hdl.handle.net/2433/109900

\section{RIGHT:}

Copyright 2009 American Institute of Physics. This article may be downloaded for personal use only. Any other use requires prior permission of the author and the American Institute of Physics. The following article appeared in APPLIED PHYSICS LETTERS 95, 231911 (2009) and may be found at http://link.aip.org/link/APPLAB/v95/i23/p231911/s1 


\title{
Correlation of dynamic and quasistatic relaxations: The Cox-Merz rule for metallic glass
}

\author{
Hidemi Kato, ${ }^{1, a)}$ Tetsu Ichitsubo, ${ }^{2}$ Hitoshi Igarashi, ${ }^{3, b)}$ and Akihisa Inoue ${ }^{1,4}$ \\ ${ }^{1}$ Institute for Materials Research, Tohoku University, Sendai 980-8577, Japan \\ ${ }^{2}$ Department of Materials Science and Engineering, Kyoto University, Kyoto 606-8501, Japan \\ ${ }^{3}$ Department of Materials Science and Engineering, Graduate School of Engineering, Tohoku University, \\ Sendai 980-8579, Japan \\ ${ }^{4}$ Tohoku University, Sendai 980-8577, Japan
}

(Received 26 September 2009; accepted 19 November 2009; published online 10 December 2009)

The correlation of quasistatic and dynamic relaxations was discussed in a typical strong $\mathrm{Zr}_{55} \mathrm{Al}_{10} \mathrm{Ni}_{5} \mathrm{Cu}_{30}$ metallic glass from room temperature to $T_{\mathrm{g}}$. The quasistatic relaxation behavior, investigated by high temperature compressive testing at a constant strain rate, was compared with dynamic tensile relaxation behavior. A correlation equation of the dynamic frequency and quasistatic strain rate was successfully deduced, and then its validity was experimentally confirmed in a fragile metallic glass. Using this correlation, the Cox-Merz rule, derived for correlating the steady-state and dynamic viscosities of the polymers, is found to be applicable to metallic glasses. (C) 2009 American Institute of Physics. [doi:10.1063/1.3272922]

In the glassy state, metallic glass exhibits a relaxation phenomenon, an essential nature of thermodynamically nonequilibrium glassy materials. This relaxation phenomenon is known to dominate the mechanical properties (elastic modulus, yield stress, and toughness ${ }^{1-4}$ ) of the glasses. In a mechanical approach, the relaxation behavior of metallic glass has been investigated by the static stress relaxation with constant strain, ${ }^{5}$ creep with constant stress, ${ }^{6}$ the quasistatic deformation with constant strain rate ${ }^{7-10}$ or the dynamic vibration with cyclic sinusoidal stress or strain. ${ }^{11-14}$ Because the elastic and viscous properties can be deduced individually from the phase difference between the stress and strain cycles, the frequency and temperature dependence of these properties can be easily obtained through frequency and temperature scans. Thus, the dynamic method is useful for investigating the relaxation behavior. This method provides information on the relaxation variation and distribution caused by the glass transition $(\alpha)$, as well as various kinds of sub- $T_{\mathrm{g}}$ relaxations $(\beta, \gamma$, etc.). Linking the information from the dynamic method to that from the (quasi) static method can provide information for further discussions on the quasistatic mechanical properties in metallic glasses, e.g., yielding, fracture, and stress-overshoot, with the dynamic relaxation characteristics. However, few reports have combined information from these modes. In this study, we investigate the temperature dependence of the quasistatic relaxation behavior from the room temperature $\left(T_{\mathrm{RT}}\right)$ to $T_{\mathrm{g}}$ in a typical strong $\mathrm{Zr}_{55} \mathrm{Al}_{10} \mathrm{Ni}_{5} \mathrm{Cu}_{30}$ bulk metallic glass, and then compare it with the dynamic relaxation behavior to deduce a correlation equation for the quasistatic strain rate and dynamic angular frequency in metallic glass.

A master ingot of $\mathrm{Zr}_{55} \mathrm{Al}_{10} \mathrm{Ni}_{5} \mathrm{Cu}_{30}$ (at. \%) was prepared by the arc-melting technique in a purified argon atmosphere. The metallic glassy rod and ribbon were prepared by copper mold casting and melt spinning techniques, respectively.

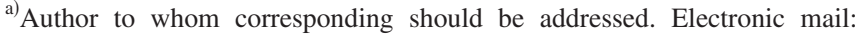
hikato@imr.tohoku.ac.jp.

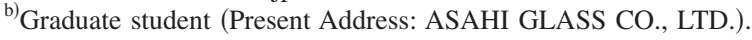

$\mathrm{X}$-ray scattering, using a $\mathrm{Cu}-\mathrm{K} \alpha$ radiation, confirmed the glassy structure of both samples. For the quasistatic high temperature compressive test, the cast rods were cut into pieces ( $2 \mathrm{~mm}$ in diameter and $4 \mathrm{~mm}$ in length) and their upper and lower planes were polished in parallel. High temperature compressive tests were carried out with a Servo Parser EHF-EA25 (Shimadzu Co. Ltd.) with a chamber filled with purified argon. For dynamic measurements the glassy ribbon $(0.03 \mathrm{~mm}$ thick) was cut into $\sim 40 \mathrm{~mm}$ long sections. Tensile dynamic tests were carried out with a Solid Analyzer RSA-II (Rheometrics, Inc.). In the present study, a sinusoidal dynamic tensile strain is applied and the replying stress is recorded. Strain amplitude is kept less than $10^{-5}$ in the linear viscoelastic state during tests.

Figure 1 shows the true compressive stress-strain (S-S) curves in $\mathrm{Zr}_{55} \mathrm{Al}_{10} \mathrm{Ni}_{5} \mathrm{Cu}_{30}$ bulk metallic glass at various isothermal testing temperatures $\left(T_{\mathrm{t}}\right)$ from $T_{\mathrm{RT}}$ to the calorimetric glass transition temperature $\left(T_{\mathrm{g}}=684 \mathrm{~K}\right.$ at a heating rate of $0.67 \mathrm{~K} / \mathrm{s})$ under a constant strain rate $(\dot{\varepsilon})$ of $1 \times 10^{-3} \mathrm{~s}^{-1}$. With increasing $T_{\mathrm{t}}$, the fracture stress $\left(\sigma_{f}\right)$ decreased gradu-

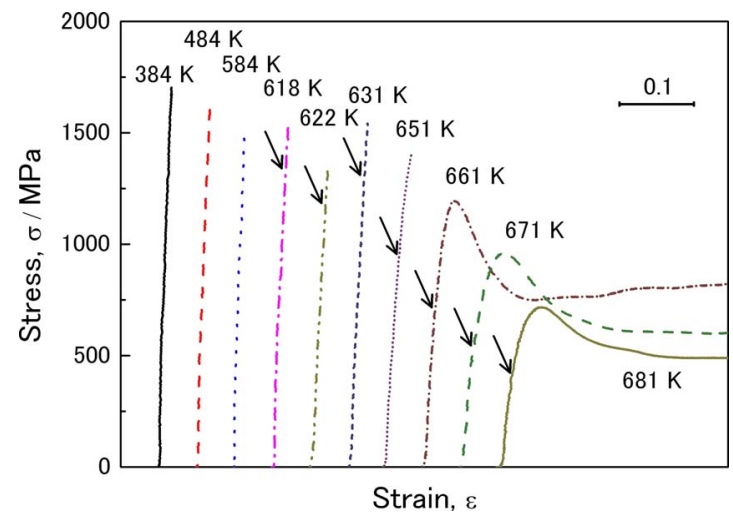

FIG. 1. (Color online) True compressive $\mathrm{S}-\mathrm{S}$ curves of a $\mathrm{Zr}_{55} \mathrm{Al}_{10} \mathrm{Ni}_{5} \mathrm{Cu}_{30}$ bulk metallic glass at various isothermal testing temperatures $\left(T_{\mathrm{t}}\right)$ varied from room temperature $\left(T_{\mathrm{RT}}\right)$ to glass transition temperature $\left(T_{\mathrm{g}}=684 \mathrm{~K}\right.$ at $0.67 \mathrm{~K} / \mathrm{s}$ ). The test strain rate is $\sim 1 \times 10^{-3} \mathrm{~s}^{-1}$. The arrows on the curves indicate the yield points. The nonlinear part observed in curves up to $\sim 200 \mathrm{MPa}$ is due to incomplete contact between the sample and the die. 


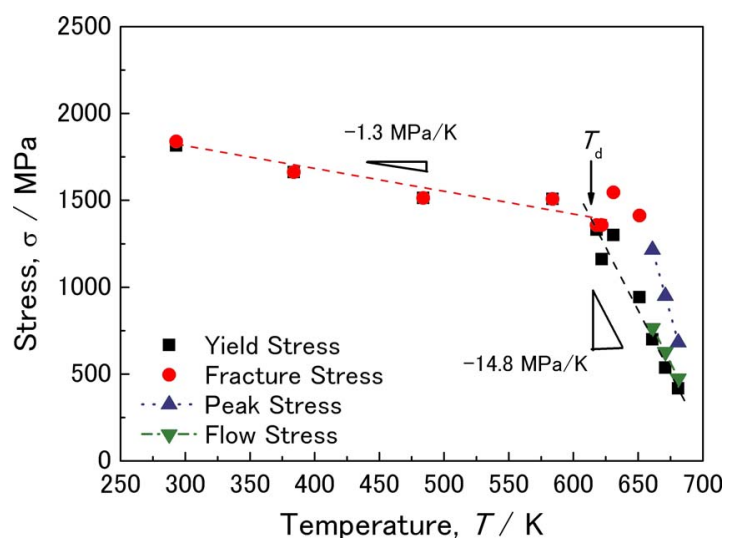

FIG. 2. (Color online) Temperature dependence of the yield stress $\left(\sigma_{y}\right)$, fracture stress $\left(\sigma_{f}\right)$, peak stress $\left(\sigma_{p}\right)$, and steady-state viscous flow stress $\left(\sigma_{s}\right)$ of a $\mathrm{Zr}_{55} \mathrm{Al}_{10} \mathrm{Ni}_{5} \mathrm{Cu}_{30}$ bulk metallic glass at a strain rate of 1 $\times 10^{-3} \mathrm{~s}^{-1}$ at various isothermal testing temperatures varied from room temperature $\left(T_{\mathrm{RT}}\right)$ to the glass transition temperature $\left(T_{\mathrm{g}}\right)$. The standard deviation on the stress is estimated to be $\sim 8 \%$.

ally. However, when $T_{\mathrm{t}}$ reached $651 \mathrm{~K}$, which is $95 \%$ of $T_{\mathrm{g}}$, an obvious yielding point, at which the S-S curve departed from the initial linear trend, began to appear. Stress and strain at the yield point and the initial linear slope are defined as yield stress $\left(\sigma_{y}\right)$, yield strain $\left(\varepsilon_{y}\right)$, and apparent Young's modulus $\left(E_{\text {ap }}\right)$, respectively, in this study. Compressive plastic elongation increased with increasing $T_{\mathrm{t}}$. When $T_{\mathrm{t}}$ reached $661 \mathrm{~K}$, which is $96 \%$ of $T_{\mathrm{g}}$, the glassy sample did not fracture any more, and the "stress-overshoot" phenomenon, followed by a steady-state non-Newtonian viscous flow, appears in the S-S curves. ${ }^{7-10}$ This overshoot tends to decrease with further increasing $T_{\mathrm{t}}$, and then almost disappears in the vicinity of $T_{\mathrm{g}}$. In the condition determined by $T_{\mathrm{t}}$ and $\dot{\varepsilon}$, the steady-state Newtonian viscous flow, which is independent of $\dot{\varepsilon}$, appeared with the steady-state flow stress $\left(\sigma_{s}\right){ }^{7-10}$ Figure 2 demonstrates the $T_{\mathrm{t}}$ dependence of $\sigma_{y}$, and $\sigma_{f}$ in addition to the peak stress $\left(\sigma_{p}\right)$ and $\sigma_{s}$ at $T_{\mathrm{t}} \geq 661 \mathrm{~K} . \sigma_{y}$ initially decreases gradually with increasing $T_{\mathrm{t}}$, with a slope of -1.3 $\mathrm{MPa} / \mathrm{K}$ from $T_{\mathrm{RT}}$, then drastically with a slope of -14.8 $\mathrm{MPa} / \mathrm{K}$ up to $T_{\mathrm{g}}$. The cross point of these linear slopes, which is considered to indicate the ductility improvement temperature $\left(T_{\mathrm{d}}\right)$ by thermal activation, is estimated to be $613 \mathrm{~K}\left(\sim 0.90 T_{\mathrm{g}}\right)$. The difference between $\sigma_{f}$ and $\sigma_{y}$ increases with increasing $T_{\mathrm{t}}$, up to $651 \mathrm{~K}$, while that between $\sigma_{p}$ and $\sigma_{y}$ tends to decrease with $T_{\mathrm{t}}$. Note that $\sigma_{y}$ has almost the same value as $\sigma_{s}$; stress returns and equilibrates finally at $\sigma_{y}$ after the stress peak. When $\sigma$ exceeds the yield point, the stress-induced structural relaxation of the glass to viscous liquid starts to be driven by a stress gap $\left(\sigma-\sigma_{y}\right){ }^{9,10}$ If the relaxation time $(\tau)$ becomes dynamically short enough to complete the whole stress-induced relaxation process $\left(\tau \ll \dot{\varepsilon}^{-1}\right)$ before fracture, the viscoelastic glassy solid succeeds in transforming into a steady-state non-Newtonian viscous liquid. However, if $\tau$ is comparable or rather longer than $\dot{\varepsilon}^{-1}$, a catastrophic localized shear fracture disturbs the completion of the relaxation process after showing a little plastic elongation. Thus, using a relaxation function, $\sigma_{y}$ can be expressed by ${ }^{15}$

$$
\sigma_{y}=E_{\mathrm{ap}} \varepsilon_{y} \approx \sigma_{s}=E_{\mathrm{u}} \dot{\varepsilon} \tau\left\{1-\exp \left[-\frac{1}{\left(\frac{\dot{\varepsilon}}{\varepsilon_{y}}\right) \tau}\right]\right\},
$$

where, $E_{\mathrm{u}}$, is the unrelaxed Young's modulus measured by the dynamic (ultrasonic) vibration, the frequency of which is significantly higher than the inverse of the relaxation time of the glass. ${ }^{1} \varepsilon_{y}$ is recognized in the polymer science field as the critical strain at which the initial glassy structure becomes further disordered dynamically. From Eq. (1a), $E_{\text {ap }}$ can be expressed by

$$
E_{\mathrm{ap}} \approx E_{\mathrm{u}}\left(\frac{\dot{\varepsilon}}{\varepsilon_{y}}\right) \tau\left\{1-\exp \left[-\frac{1}{\left(\frac{\dot{\varepsilon}}{\varepsilon_{y}}\right) \tau}\right]\right\} .
$$

The viscoelasticity of a glassy solid has been well measured by various dynamic methods because the viscous effect causes a phase shift between the sinusoidal strain and stress waves. The dynamic complex modulus $\left(E^{*}\right)$ of the Maxwell element, which is sometimes used for predicting the viscoelastic behavior of metallic glasses, can be expressed by ${ }^{16}$

$$
\left|E^{*}\right|=\sqrt{\left(E^{\prime}\right)^{2}+\left(E^{\prime \prime}\right)^{2}}=E_{\mathrm{u}} \frac{\omega \tau}{\left(1+\omega^{2} \tau^{2}\right)^{1 / 2}},
$$

where $E^{\prime}, E^{\prime \prime}$, and $\omega$ are the storage modulus corresponding to the elastic energy, the loss modulus corresponding to the energy spent as heat or a phase or structural change in a dynamic cycle, and the angular frequency $\left(\mathrm{rad} \mathrm{s}^{-1}\right)$, respectively. If we use an approximation, ${ }^{15}$

$$
\frac{1}{\left[1+\omega^{2} \tau^{2}\right]^{1 / 2}} \cong 1-\exp \left(-\frac{1}{\omega \tau}\right)
$$

Equation (2) yields

$$
\left|E^{*}\right| \cong E_{\mathrm{u}} \omega \tau\left[1-\exp \left(-\frac{1}{\omega \tau}\right)\right] .
$$

The approximation by Eq. (3) works well in both $\omega \tau \ll 1$ and $\omega \tau \gg 1$, and causes a maximum error of $\sim 10 \%$ around $\omega \tau$ $\sim 2$. Considering the physical meaning of $\left|E^{*}\right|\left(\approx E^{\prime}\right.$ when $T_{\mathrm{t}}<T_{\mathrm{g}}$ ), this value equals $E_{\mathrm{ap}}$, although the deformation mode is different, i.e., dynamic and quasistatic modes,

$$
\left|E^{*}\right|=E_{\text {ap }} .
$$

Therefore, we finally obtain a correlation of $\omega$ and $\dot{\varepsilon}$ by comparing Eqs. (1b) and (4),

$$
\omega=\frac{1}{\varepsilon_{y}} \dot{\varepsilon} .
$$

Although $\varepsilon_{y}$ shows a little $T_{\mathrm{t}}$ dependence, especially in $T$ $>T_{\mathrm{d}}$, for convenience, we assume $\varepsilon_{y} \sim 0.02$ in Eq. (6) for $T_{\mathrm{RT}} \leq T_{\mathrm{t}} \leq T_{\mathrm{g}}$. Figure $3(\mathrm{a})$ demonstrates $T_{\mathrm{t}}$ dependence of $E_{\text {ap }}$ at $\dot{\varepsilon}=1 \times 10^{-3} \mathrm{~s}^{-1}$ obtained from Fig. 1 . $E_{\text {ap }}$ decreases gradually up to $T_{\mathrm{d}}$, then drastically with increasing $T_{\mathrm{t}}$ in the same manner as $\sigma_{y}$ (see Fig. 2). From Eq. (6), $\omega$, which effectively corresponds to $\dot{\varepsilon}$, is estimated at $\sim 50 \times 1 \times 10^{-3}$ $=5 \times 10^{-2} \mathrm{rad} \mathrm{s}^{-1}$. Using a melt-spun ribbon of the same metallic glass, $E^{*}$ at $\omega=5 \times 10^{-2} \mathrm{rad} \mathrm{s}^{-1}$ is measured from $T_{\mathrm{RT}}$ up to $T_{\mathrm{g}}$, then compared with $E_{\mathrm{ap}}$ in Fig. 3(a). Figure 3(b) also demonstrates $E^{*}$ and corresponding $E_{\text {ap }}$ in a typical fragile $\mathrm{Pd}_{40} \mathrm{Ni}_{10} \mathrm{Cu}_{30} \mathrm{P}_{20}$ metallic glass. ${ }^{17}$ In both typically 


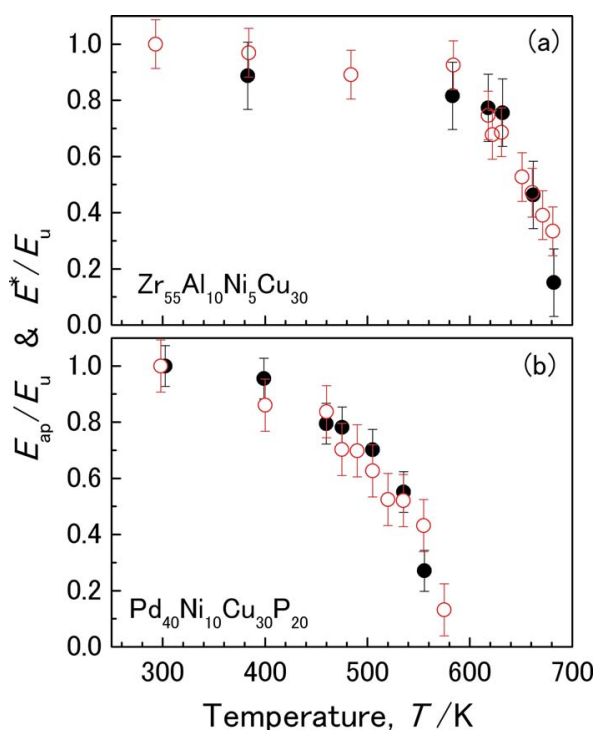

FIG. 3. (Color online) Isothermal testing temperature dependence of the apparent Young's modulus $\left(E_{\text {ap }}\right)$ at a quasistatic strain rate of $1 \times 10^{-3} \mathrm{~s}^{-1}$ and of the complex modulus $\left(E^{*}\right)$ at a dynamic angular frequency of 5 $\times 10^{-2} \mathrm{rad} \mathrm{s}^{-1}$ from room temperature $\left(T_{\mathrm{RT}}\right)$ to the glass transition temperature $\left(T_{\mathrm{g}}\right)$ in a strong $\mathrm{Zr}_{55} \mathrm{Al}_{10} \mathrm{Ni}_{5} \mathrm{Cu}_{30}$ metallic glass $\left(T_{\mathrm{g}} \sim 684 \mathrm{~K}\right.$ at $\left.0.67 \mathrm{~K} / \mathrm{s}\right)$ (a) and in a fragile $\mathrm{Pd}_{40} \mathrm{Ni}_{10} \mathrm{Cu}_{30} \mathrm{P}_{20}$ metallic glass $\left(T_{\mathrm{g}} \sim 575 \mathrm{~K}\right.$ at $\left.0.67 \mathrm{~K} / \mathrm{s}\right)$ (b). The strain rate and angular frequency satisfy Eq. (6) with $\varepsilon_{y}=0.02$. Open and solid symbols indicate data for the quasistatic apparent Young's modulus and dynamic complex modulus both of which are normalized by the Young's modulus at $T_{\mathrm{RT}}$.

strong and fragile metallic glasses, $E^{*}$ is in good agreement with $E_{\text {ap }}$; this experimentally confirms that Eq. (6) can adequately bridge between the dynamic and quasistatic relaxations in metallic glass with $\varepsilon_{y} \sim 0.02$.

The dynamic complex viscosity $\left[\eta^{*}(\omega)\right]$ is defined by

$$
\left|\eta^{*}\right|=\frac{\left|E^{*}\right|}{3 \omega} \text {. }
$$

From Eqs. (1a) and (4), Eq. (7) yields

$$
\begin{aligned}
\left|\eta^{*}\right| & \cong \frac{E_{\mathrm{u}} \omega \tau}{3 \omega}\left[1-\exp \left(-\frac{1}{\omega \tau}\right)\right] \\
& \approx \frac{E_{\mathrm{u}} \tau}{3}\left\{1-\exp \left[-\frac{1}{\left.\left.\left(\frac{\dot{\varepsilon}}{\varepsilon_{y}}\right) \tau\right]\right\}=\eta_{s},}\right.\right.
\end{aligned}
$$

where, $\eta_{s}$ is the steady-state flow viscosity. In polymer science, Eq. (8) is well known as the Cox-Merz rule, ${ }^{18}\left|\eta^{*}\right|$ $=\eta_{S}$ when $\varepsilon_{y}^{-1}$ is on the order of one for polymer melts, and $10^{1}$ for polymer glasses. ${ }^{15}$ The present work shows that the Cox-Merz rule is applicable for metallic glasses with $\omega \approx 50 \dot{\varepsilon}$, from Eq. (6).
In this study, the quasistatic relaxation behavior in a $\mathrm{Zr}_{55} \mathrm{Al}_{10} \mathrm{Ni}_{5} \mathrm{Cu}_{30}$ metallic glass was observed through the elastic modulus and stress, measured by high temperature compressive tests. Based on the results that the yield stress is comparable to the steady-state flow stress, and the yield strain at which the linear viscoelasticity breaks down into the nonlinear state maintaining an almost constant value of $\sim 0.02$ from $T_{\mathrm{RT}}$ to $T_{\mathrm{g}}$, a correlation equation of the dynamic angular frequency and quasistatic strain rate was successfully deduced, and then confirmed by experimental results with both fragile and strong metallic glasses. This correlation is expected to enhance further understanding of the relaxation phenomenon of metallic glasses and the mechanical properties or viscous workability from the scientific and engineering viewpoints, respectively.

The present study was supported by New Energy and Industrial Technology Development Organization (NEDO) under "Technological Development of Innovative Components Based on Enhanced Functionality Metallic Glass" project, and was performed under the Interuniversity Cooperative Research Program of the Institute for Materials Research (IMR), Tohoku University.

${ }^{1}$ T. Ichitsubo, S. Kai, H. Ogi, M. Hirao, and K. Tanaka, Scr. Mater. 49, 267 (2003).

${ }^{2}$ H. Kato, H. Igarashi, and A. Inoue, Mater. Lett. 62, 1592 (2008).

${ }^{3}$ R. Raghavan, P. Murali, and U. Ramamurty, Intermetallics 14, 1051 (2006).

${ }^{4}$ P. A. Hess and R. H. Dauskardt, Acta Mater. 52, 3525 (2004).

${ }^{5}$ O. P. Bobrov, K. Csach, V. A. Khonik, K. Kitagawa, S. N. Laptev, and M. Yu Yazvitsky, Scr. Mater. 54, 369 (2006).

${ }^{6}$ O. P. Bobrov, V. A. Khonik, S. A. Lyakhov, K. Csach, K. Kitagawa, and H. Neuhauser, J. Appl. Phys. 100, 033518 (2006).

${ }^{7}$ H. Kato, Y. Kawamura, A. Inoue, and H. S. Chen, Appl. Phys. Lett. 73, 3665 (1998).

${ }^{8}$ J. Lu, G. Ravichandran, and W. L. Johnson, Acta Mater. 51, 3429 (2003).

${ }^{9}$ H. S. Kim, H. Kato, A. Inoue, and H. S. Chen, Acta Mater. 52, 3813 (2004); H. S. Kim, H. Kato, A. Inoue, H. S. Chen, and S. I. Hong, Mater. Trans. 45, 1228 (2004).

${ }^{10}$ H. Kato, A. Inoue, and H. S. Chen, Acta Mater. 54, 891 (2006).

${ }^{11}$ D. N. Perera and A. P. Tsai, J. Phys.: Condens. Matter 11, 3029 (1999).

${ }^{12}$ Z. F. Zhao, P. Wen, C. H. Shek, and W. H. Wang, Phys. Rev. B 75, 174201 (2007).

${ }^{13}$ P. Rosner, K. Samwer, and P. Lunkenheimer, Europhys. Lett. 68, 226 (2004).

${ }^{14}$ Q. Wang, J. M. Pelletier, H. Xu, L. Xia, X. H. Tan, and Y. D. Dong, J. Mater. Sci. 40, 4795 (2005).

${ }^{15}$ S. Matsuoka, Relaxation Phenomena in Polymers (Oxford University Press, New York, 1992).

${ }^{16}$ J. D. Ferry, Viscoelastic Properties of Polymers, 3rd ed. (Wiley, New York, 1980).

${ }^{17}$ H. Kato, T. Wada, M. Hasegawa, J. Saida, A. Inoue, and H. S. Chen, Scr. Mater. 54, 2023 (2006).

${ }^{18}$ W. P. Cox and E. H. Merz, J. Polym. Sci. 28, 619 (1958). 